\title{
Sujeito Nulo e Ordem Verbo-Sujeito no português brasileiro: análise diacrônica
}

\section{Null subject and verb-subject order in Brazilian Portuguese: diachronic analysis}

\author{
Maria Eugênia Lammoglia Duarte \\ Universidade Federal do Rio de Janeiro (Brasil) \\ engenia@brazilmail.com
}

Humberto Soares da Silva

Universidade Federal do Rio de Janeiro (Brasil)

humberto@letras.ufrj.br

\section{Resumo}

Este artigo apresenta evidências empíricas de que a mudança na remarcaçáo do valor do Parâmetro do Sujeito Nulo no português brasileiro desencadeia o desaparecimento de outras estruturas elencadas entre os feixes de propriedades relacionadas às línguas [+Sujeito Nulo] do grupo românico. A pesquisa se baseia em evidências diacrônicas e sincrônicas, que provêm de estudos que analisaram os diferentes fenômenos, todos associados a propriedades do Parâmetro do Sujeito Nulo, a partir das falas de roteiros de peças de teatro escritas no Rio de Janeiro ao longo dos séculos 19 e 20 e de entrevistas sociolinguísticas com falantes cariocas. Ao comparar, sistematizar e analisar os resultados desses estudos em conjunto, mostramos que, à medida que os sujeitos pronominais, tanto de referência definida quanto indeterminada, se tornam pronomes foneticamente realizados, a ordem verbo-sujeito é afetada, tanto em estruturas com verbos inacusativos como em interrogativas $Q$. A realização fonética do sujeito expletivo, que seria um efeito colateral esperado para essa mudança, não é atestada. No entanto, outras estratégias são implementadas no sistema, entre as quais o alçamento de constituintes para evitar um expletivo nulo, o que é compatível com um sistema com proeminência de tópico, que caracteriza o português brasileiro.

\section{Palavras-chave}

mudança paramétrica; Parâmetro do Sujeito Nulo; sujeitos referenciais; sujeitos expletivos; ordem verbo-sujeito; construçóes de alçamento

\section{Sumário}

1. Introducão. 2. Do pronome nulo ao pronome pleno - evidências diacrônicas e sincrônicas. 3. A ordem V-DP/DP-V em sentenças com verbos inacusativos: diacronia e sincronia. 4. As sentenças interrogativas: evidências diacrônicas e sincrônicas do preenchimento e da ordem. 5. O alçamento a partir de uma oração subordinada: estudos diacrônicos e sincrônicos. 6 . Conclusão.
Recibido o 12/05/2018

Aceptado o 05/03/2019

\section{Abstract}

This article provides empirical evidence that the process of change in the resetting of the value of the Null Subject Parameter in Brazilian Portuguese (BP) triggers the disappearance of other structures associated with the cluster of properties related to $[+\mathrm{Null}$ Subject] Romance languages. This research takes as basis diachronic and synchronic data, from studies that analysed several phenomena associated to Null Subject Parameter properties using plays written in Rio de Janeiro in the 19th and 20th centuries and sociolinguistic interviews with speakers from Rio de Janeiro. By comparing, systematising and analysing the results of these studies, we show that, as referential and indeterminate subjects become overt pronouns, verb-subject order is affected not only with unaccusative verbs but also in WH questions as well. The development of a lexical expletive, which should be an expected side effect of the change, is not attested. However, the system reveals the implementation of other strategies, such as the raising of constituents, in order to avoid a null expletive, which is in line with the topic prominence which characterises Brazilian Portuguese.

\section{Keywords}

Parametric change; Null Subject Parameter; referential subjects; expletive subjects; verb-subject order; raising structures

\section{Contents}

1. Introduction. 2. From null to overt pronoun - diachronic and synchronic evidences. 3. V-DP/DP-V order in sentences with unaccusative verbs: diachronic and synchronic studies. 4. Interrogative sentences: diachronic and synchronic evidence of overtness and order. 5. Raising from an embedded clause: diachronic and synchronic studies. 6. Conclusion. 


\section{Introdução}

$\mathrm{O}$ PORTUGUÊs brasileiro (PB) tem sido considerado em análise recentes uma língua de sujeito nulo parcial, que licencia sujeitos nulos referenciais em contextos estruturais bastante restritos e mantém sujeitos não-referenciais nulos (Holmberg 2010; Roberts \& Holmberg 2010). Nosso objetivo é mostrar que o PB não se revela como um sistema estável de língua de sujeito nulo parcial, nem no que diz respeito aos sujeitos referenciais nem no que diz respeito aos não-referenciais (ou expletivos). Nosso argumento se sustenta no fato de que ambos os tipos de sujeito - referenciais e não-referenciais - não se encontram em distribuição complementar; antes, o que se observa no PB contemporâneo é uma competição entre sujeitos nulos e expressos, disputando os mesmos contextos estruturais. Além disso, como mostraremos, o PB ainda exibe sujeitos nulos referenciais em todos os contextos em que uma LSN românica os licencia. À medida que a mudança progride em direção aos sujeitos referenciais expressos, os índices de sujeitos nulos vão decrescendo a partir dos contextos de menor acessibilidade sintática.

Enquanto os nulos referenciais ainda se mostram em competição com pronomes plenos, os expletivos nulos aparecem em competiçáo com constituintes alçados para a posição estrutural do sujeito (sujeitos de oraçóes encaixadas, genitivos, dativos, locativos) ${ }^{1}$, ou com elementos inseridos nessa posição, como demonstrativos e pronomes pessoais, entre outras estratégias. Os sujeitos nulos referenciais que ainda ocorrem no PB aparecem nas três pessoas do discurso, o que não ocorre no Finlandês, que tem um sistema sujeitos nulos opcionais de $3^{\mathrm{a}}$. pessoa em encaixadas se controlado pelo sujeito da matriz. Quanto aos sujeitos expletivos, o Finlandês tem um expletivo sitä, o que náo ocorre no $\mathrm{PB}$. A hipótese de que o $\mathrm{PB}$ é uma língua com proeminência de tópico (Li \& Thompson 1976), em que elementos sem conteúdo semântico não têm representação fonética em línguas orientadas para o discurso ${ }^{2}$, pode explicar essas operaçóes de alçamento para ocupar a posição estrutural do sujeito.

Nossa hipótese para o quadro observado no comportamento do PB é que estamos diante de uma etapa no processo da mudança na remarcaçáo do valor do Parâmetro do Sujeito Nulo (PSN): de [+Sujeito Nulo], o PB passa a [-Sujeito Nulo]. Evidência adicional dessa mudança vem da alteração em uma das propriedades atribuídas às línguas [+Sujeito Nulo] do grupo românico: a chamada "inversão livre" do sujeito,

1. expl. Parece que eu vou explodir de raiva vs $\mathrm{Eu}_{\mathrm{i}}$ pareço que $t_{\mathrm{i}} /$ eu vou explodir $\mathrm{d}$ raiva.

expl. Caíram [as flores daquelas árvores] vs [As flores daquelas árvores] caíram vs [Aquelas árvores] ${ }_{\mathrm{i}}$ caíram [as flores $\mathrm{t}_{\mathrm{i}}$ ].

expl. Faltou sorte [ao meu time] vs [Meu time $]_{\mathrm{i}}$ faltou sorte $[\mathrm{t}]_{\mathrm{i}}$

expl. Bate sol [naquelas janelas] vs [Aquelas janelas $]_{i}$ batem sol $[\mathrm{t}]_{\mathrm{i}}$

expl. Era em torno de duas horas vs Isso / Aquilo era em torno de duas horas.

2. "In a $\mathrm{Tp}$ (topic prominent) language, where the notion of subject does not play a prominent role, there is no need for 'dummy' subjects" ( $\mathrm{Li}$ and Thompson, 1976: 467). 
que se refere à ordem VS para expressar juízo tético nas LSN românicas e está condicionada ao número de argumentos foneticamente realizados como DPs lexicais (Zubizarreta 1998). Veremos que a mudança afeta a ordem verbo-sujeito (VS) não só nos contextos de com inacusativos ou com verbos que tem uma de seus argumentos realizados como clítico ou nulo - predicados menos pesados, mas também em outros contextos, como as interrogativas-Q, o que justifica a inclusão do PB entre as línguas positivamente marcadas em relação ao PSN.

Os dados diacrônicos para nossa análise provêm de peças de teatro popular, escritas e ambientadas no Rio de Janeiro, ao longo dos séculos 19 e 20. Evidências adicionais vêm de análises sincrônicas realizadas a partir de entrevistas sociolinguísticas com falantes do Rio de Janeiro. O trabalho associa o modelo de estudo da mudança da Sociolinguística Variacionista (Weinreich, Labov \& Herzog 1968) com desenvolvimentos recentes da Teoria de Princípios e Parâmetros. Este artigo está organizado da seguinte maneira: na seçáo 1, apresentamos a diacronia do preenchimento do sujeito referencial no PB, apontando como se dá o percurso da mudança na amostra de teatro popular, considerando o contexto estrutural e a relaçáo sujeito e seu antecedente, além do traço semântico do referente. A seção se encerra com resultados obtidos para a fala espontânea, a partir de entrevistas realizadas no mesmo ano da última sincronia das peças de teatro. A seção 2 mostra o efeito da mudança na ordem de constituintes em sentenças com verbo inacusativo, que constituem os contextos mais favoráveis à inversão livre nas línguas de sujeito nulo. Como se verá, a escrita das peças bem como a fala das entrevistas sociolinguísticas mostram os contextos em que mais prontamente se implementa a mudança. Além disso, uma análise de sites de reclamação da internet permite atestar o que vem sendo apontado como uma típica construção de alçamento de genitivo (nota 1) com esse tipo de verbo, conhecida como "tópico-sujeito". Em 3, apresentamos outro estudo, sobre a mudança na ordem VS para sujeito-verbo (SV) nas interrogativas Q. Geralmente dissociada do PSN, a mudança observada no PB corre paralelamente ao preenchimento do sujeito. Finalmente, em 4, são analisadas as construções de alçamento envolvendo "verbos de alçamento" ou "de elevação", que selecionam uma oração complemento. Como se verá, o alçamento do sujeito da encaixada para a posição estrutural do sujeito da oração matriz é mais uma estratégia para evitar um expletivo nulo. Concluímos o artigo com algumas consideraçóes sobre a importância de análises empíricas de longo termo associadas a análises da fala espontânea e de outros tipos de amostras que permitam capturar o vernáculo para generalizaçóes acerca da mudança envolvendo a remarcação do valor de um parâmetro da Gramática Universal. Nossos resultados confirmam a hipótese levantada por Biberauer (2010), para quem o rótulo parcial pode abarcar sistemas muito desiguais, o que exige um exame rigoroso dos contextos que licenciam sujeitos nulos e da sintaxe das sentenças impessoais. 


\section{Do pronome nulo ao pronome pleno - evidências diacrônicas e sincrônicas}

A análise de Duarte (1993), com base em peças de teatro popular, escritas ao longo dos séculos 19 e 20, mostrou um expressivo aumento de sujeitos pronominais expressos, com momentos de transição coincidindo com mudanças no paradigma pronominal, que afetavam diretamente o quadro de oposiçóes no sistema flexional dos verbos. A Tabela 1, com a conjugação do estudar, exemplifica tais mudanças:

\begin{tabular}{|c|c|c|c|c|}
\hline PESSOA & PRONOME PESSOAL & PARADIGMA I & PARADIGMA 2 & PARADIGMA 3 \\
\hline 1. ${ }^{a}$ SINGULAR & $\mathrm{eu}$ & estud $o$ & estud $o$ & estudo \\
\hline \multirow{2}{*}{ 2. ${ }^{\mathrm{a}}$ SINGULAR } & $\mathrm{tu}$ & estudas & estudas & estuda(s) \\
\hline & você & --.-- & estuda & estuda \\
\hline 3. ${ }^{\mathrm{a}}$ SINGULAR & ele, ela & estuda & estuda & estuda \\
\hline \multirow{2}{*}{ 1. ${ }^{a}$ PLURAL } & nós & estudamos & estudamos & estudamos \\
\hline & a gente & ----- & estuda & estuda \\
\hline \multirow{2}{*}{ 2. ${ }^{a}$ PLURAL } & vós & estudais & ----- & --.-- \\
\hline & vocês & ----- & estuda $m$ & estudam \\
\hline 3. ${ }^{a}$ PLURAL & eles, elas & estudam & estudam & estudam \\
\hline
\end{tabular}

Tabela 1. Evolução do paradigma pronominal e flexional do verbo estudar (Duarte 1993)

O sistema pronominal que aparece nas peças escritas no século 19 e no primeiro quartel do século 20 (Paradigma 1) ainda não exibe o pronome você, que viria a se implementar a partir dos anos 1930 na amostra analisada. Esse novo pronome de segunda pessoa, resultado da gramaticalização da forma de tratamento Vossa Mercê, que aparece sistematicamente no Paradigma 2 (relativo aos anos 1930), substituiria o pronome tu em boa parte do país, ou conviveria com ele, perdendo completamente o grau de menor intimidade que ainda caracteriza o uso de você em Portugal. No Brasil, além de ambos se alternarem nas regiōes em que convivem, a desinência exclusiva do verbo com o pronome $t u$ (-s) é geralmente apagada, neutralizando-se a forma verbal para a segunda pessoa do singular. Juntamente com a pronominalização de você, sua forma plural vocês substituiria o pronome vós, para referência à segunda pessoa do plural, completamente extinto no paradigma pronominal do $\mathrm{PB}$.

Um novo pronome para a referência à primeira pessoa do plural, igualmente resultado da gramaticalização do sintagma a gente (Lopes 2003), se insere plenamente no quadro pronominal em competição com o pronome nós, passando a ser a forma vitoriosa a partir dos anos 1975, na amostra analisada. Se se leva em conta o fato de que o pronome nós está em franco desaparecimento na fala brasileira e que a queda do -s nas formas verbais de segunda pessoa relacionada ao pronome tu é a mais usual, vemos que o Paradigma 3 apresenta apenas três formas distintivas. 
A Figura 1, além de permitir observar os momentos de transição no paradigma pronominal/flexional do $\mathrm{PB}$, mostra que a mudança em direçáo a pronomes expressos não é uniforme em relação às pessoas do discurso:

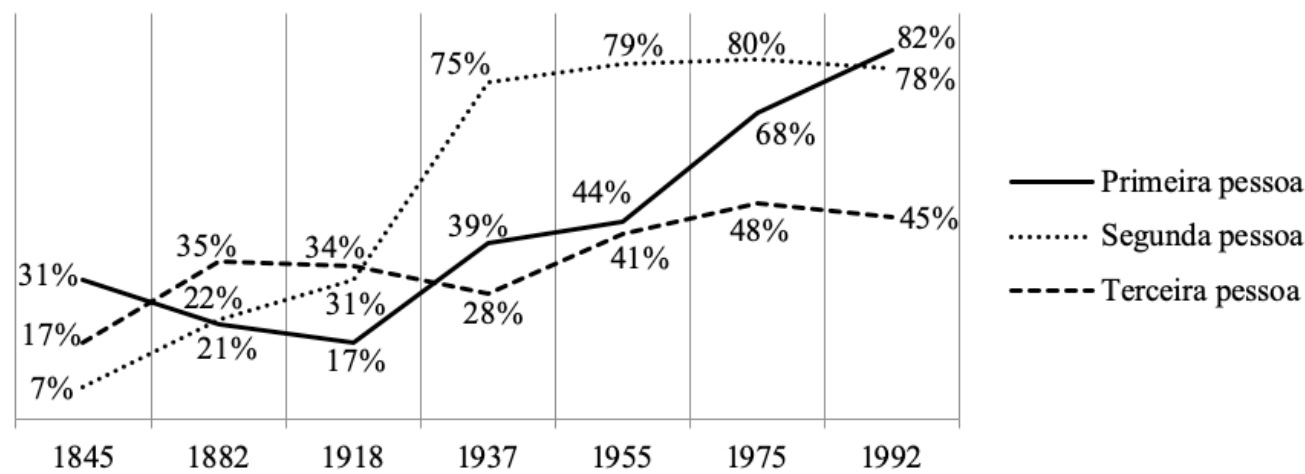

Figura 1. Sujeitos expressos (vs. nulos) segundo a pessoa do discurso ao longo do tempo - adaptado de Duarte $(1993: 117)^{3}$

Nas três primeiras sincronias, o que significa ao longo do século 19 e no primeiro quartel do século 20, vemos um comportamento regular para as três pessoas, com índices de sujeitos expressos sempre inferiores aos sujeitos nulos, o que se espera de um sistema positivamente marcado em relação ao PSN. A partir dos anos 1930, quando o Paradigma 2 se implementa nas peças, vemos um importante momento de transição.

(a) A segunda pessoa, que exibia 7\%, 22\% e 31\% de pronomes expressos - restritos ainda a tu e formas de cortesia, como $o($ a) senhor (a) -, passa, com a gramaticalização de você, a $75 \%$ e chega a $78 \%$ nos anos 1922, uma mudança praticamente concluída, se considerarmos que os nulos residuais são pragmaticamente recuperados, aparecendo em oraçóes raízes e especialmente em perguntas. Os exemplos ilustram os dois padróes prototípicos, antes e depois da mudança. Veja-se que, mesmo na oração encaixada em (1b), temos o sujeito correferente com o da matriz expresso, um importante traço de língua [-Sujeito Nulo]:

3. Neste e nos outros resultados de estudos diacrônicos, priorizamos demonstrar a evoluçáo das frequências de realização ao longo dos sete períodos considerados, para evidenciar a transição e a implementação da mudança em progresso, em vez de apresentar as estatísticas dos estudos variacionistas que geraram essas taxas. Convidamos o leitor a consultar resultados mais detalhados sobre os condicionamentos nos estudos citados junto às tabelas de resultados diacrônicos. 
(1) a. Madalena: Acalme-se "miss", que tudo se há de arranjar. $\varnothing_{2 \mathrm{ps}}$ Terá o cavalo que $\varnothing_{2 \mathrm{ps}}$ deseja. ${ }^{4}$

(O simpático Jeremias, Gastão Tojeiro 1918)

b. Margareth: Você não entende meu coração porque você 'tá sempre olhando pro céu e procurando chuva.

(No coração do Brasil, Miguel Falabella 1992)

(b) A primeira pessoa, inicialmente com $31 \%$ de sujeitos expressos, particularmente em casos de VS, num uso enfático, como mostrado em (2), mantém índices baixos, com $21 \%$ e $17 \%$ de preenchimento. A preferência, nas três primeiras sincronias do estudo, é pelo sujeito nulo, exemplificado em (3a). A partir da peça de 1938, inicia uma curva ascendente, menos brusca mas consistente, em direção ao sujeito expresso (3b), alcançando $82 \%$ na última sincronia.

(2) a. Ambrósio: Há oito anos, era eu pobre e miserável, e hoje sou rico e mais ainda serei.

b. Florência: Que sacrifícios não farei eu para ventura de meus filhos!

c. Ambrósio: Outros tenho eu domado

(O Noviço, Martins Pena 1845)

(3) a. Ambrósio: Quando $\varnothing_{1 \mathrm{ps}}$ te vi pela primeira vez, $\varnothing_{1 \mathrm{ps}}$ náo sabia que $\varnothing_{2 \mathrm{ps}}$ eras viúva e rica. $\varnothing_{1 \mathrm{ps}} A m e i$-te por simpatia.

(O noviço, Martins Pena 1845)

b. Nilson: Eu só estou repetindo o que eu li.

(No coração do Brasil, Miguel Falabella 1992)

(c) A terceira pessoa é a que apresenta maior resistência à mudança, revelando $17 \%$ de sujeitos expressos na primeira sincronia para chegar a $45 \%$ na última. Trata-se de um aumento de quase $30 \%$, mas é inegável que este constitui um contexto de resistência à implementação da mudança. A transição ocorre na segunda metade do século 20. Uma revisita ao artigo de Duarte (1993), que incluiu o aumento da amostra para a análise da terceira pessoa (Duarte, Mourão e Santos 2012), revela que o padrão sentencial (Barbosa, Duarte e Kato 2005) importa pouco num sistema [+Sujeito Nulo]: o sujeito será preferencialmente nulo seja com um antecedente em outra função sintática (4a) ou distante da sua retomada (4b), desde que sua interpretação não seja comprometida; estando o antecedente na mesma função, seja na oraçáo que o precede seja no período adjacente (4c-d), o sujeito nulo é a realização não marcada:

4. Os exemplos retirados das peças são precedidos do nome do personagem a que a fala é atribuída. Entre parênteses, estấo indicados o título da peça (em itálico), seu autor e o ano em que foi escrita. 
(4) a. Florência: Espere, vizinho, deixe-me sair primeiro. Se $o_{i}$ encontrarem, dêem-lhe uma boa arrochada e levem-no ${ }_{\mathrm{i}}$ preso. $\varnothing_{\mathrm{i}}$ Há de me pagar!

(O noviço, Martins Pena 1845)

b. Carolice: [Este menino $]_{\mathrm{i}}$ forma um verdadeiro contraste comigo! Se eu não tivesse a certeza... era capaz de jurar que $\varnothing_{\mathrm{i}}$ não era meu filho!...

(A vida tem três andares, Humberto Cunha 1938)

c. Nestório: [O Ventura $]_{\mathrm{i}}$ tem um livro onde $\varnothing_{\mathrm{i}}$ escritura todo o dinheiro que $\varnothing_{\mathrm{i}}$ pede.

(O hóspede do quarto $n^{\circ}$ 2, Armando Gonzaga 1937)

d. Cristina: Ele $e_{i}$ adora minha comida. $\varnothing_{\mathrm{i}}$ Já deve estar chegando.

(A mulher integral, Carlos Eduardo Novaes 1975)

Em períodos mais recentes, os sujeitos nos padrôes em (4a) e (4b) já são quase categoricamente expressos, havendo variação nos dois últimos, exatamente aqueles em que o antecedente é mais acessível sintaticamente. Há, ainda, uma variação mais equilibrada nos dois últimos padrốes sentenciais. Comparem-se (5a-b) e (6a-b):

(5) a. Laura: Ele diz que $\varnothing_{\mathrm{i}}$ está sozinho na Delegacia, que o guarda da noite está jantando.

(Do tamanho de um defunto, Millôr Fernandes 1955)

b. Dolores: Agora ele não vai mais poder dizer as coisas que ele $e_{\mathrm{i}}$ queria dizer.

(No coração do Brasil, Miguel Falabella 1992)

(6) a. Limoeiro: $[\mathrm{O} \text { tenente-coronel }]_{\mathrm{i}}$ ainda nao veio?

Perpétua: $\varnothing_{\mathrm{i}}$ Está lá dentro.

(Como se fazia um deputado, França Júnior 1882)

b. Maria Lúcia: Laurinha ${ }_{\mathrm{i}}$ me ligou ontem, de Berlim. Ela $\mathrm{i}_{\mathrm{i}}$ está contente com a bolsa de estudo, e o dinheiro do apartamento ajudou muito.

(A Partilha, Miguel Falabella 1989)

Além do padrão estrutural, um fator que atua fortemente no progresso da mudança e que explica os índices mais baixos de nulos de $3^{\mathrm{a}}$. pessoa é o feixe de traços semânticos do referente. A referida análise de Duarte, Mourão e Santos (2012) confirma que referentes com os traços [+humano/+específico] revelam a mesma curva ascendente observada para a primeira e segunda pessoas, enquanto os que têm o traço [-humano] revelam maior resistência ao pronome expresso, embora já ocorram em percentuais expressivos nos períodos mais recentes. Da mesma forma, os sujeitos indeterminados (que excluem, incluem necessariamente ou podem incluir o falante, como exemplificam $7 \mathrm{a}, \mathrm{b}, \mathrm{c}$, respectivamente, seguem a mesma tendência ao preenchimento por um pronome nominativo. Esse resultado confirma a atuaçáo de uma hierarquia referencial (Cyrino, Duarte \& Kato 2000) em processos de mudança envolvendo pronomes. 
(7) a. Maria: Já! Eu ouvi no rádio que eles estavam decretando. Que horror! E esse rapaz por aí. Tenho medo que lhe aconteça alguma coisa.

(Um elefante no caos, Millôr Fernandes 1955)

b. Justino: Por essas e outras é que a gente perde a paciência.

(Onde canta o sabiá..., Gastáo Tojeiro 1920)

c. Neiva: E esse chá, se você toma bem quente é batata!

(No coração do Brasil, Miguel Falabella 1992)

A Figura 2 representa a linha para os sujeitos de terceira pessoa com o o traço [+hum/+esp] e os sujeitos de referência indeterminada:

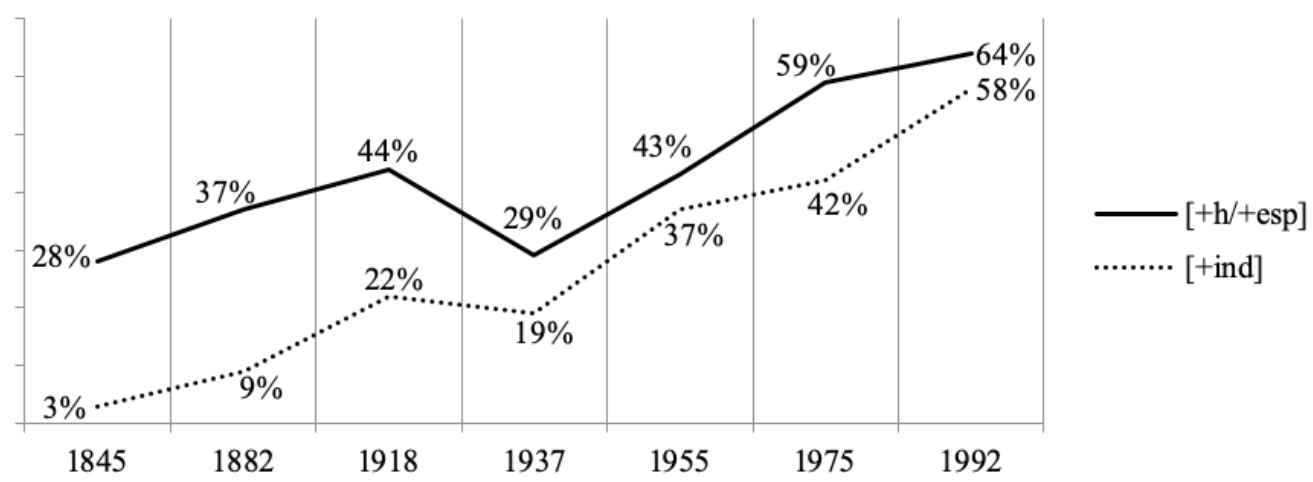

Figura 2. Sujeitos expressos (vs. nulos) com o traço [+hum/+esp] e o traço [+indeterminado] - adaptado de Duarte, Mourão e Santos (2012) e Vargas (2012)

Não representamos na Figura 2 as linhas para os demais tipos semânticos de referente, mas os resultados indicam que, embora mais lentamente, os sujeitos vão sendo preenchidos por pronomes pessoais, como exemplificamos em (8), que ilustra um sujeito [+hum/-esp] e um sujeito [-hum/+esp], que revela a perda de uma propriedade que caracteriza as línguas românicas de sujeito nulo, que náo retomam referentes [-hum] com um pronome pessoal:

(8) a. Dona Irene: Não é culpa dele, Holly. Está provado que, se [a criança $]_{\mathrm{i}}$ não recebe uma alimentacão eficaz, ela ${ }_{\mathrm{i}}$ fica em desvantagem para o resto da vida.

(No coração do Brasil, Miguel Falabella 1992)

b. Ladrão: Aliás, eu não assaltei [a casa do lado] $]_{\mathrm{i}}$, porque ela está na jurisdição do $14 .^{\circ}$ Distrito.

(Do tamanho de um defunto, Millôr Fernandes 1955) 
Os resultados aqui apresentados dáo a ideia da gradualidade da mudança, permitindo observar a perda de propriedades que não se ajustam a um sistema românico de sujeitos nulos: o pronome de retomada expresso em subordinadas e o uso do pronome pessoal para referentes com o traço [-hum]. Quando observada em amostra de fala espontânea, gravada exatamente em 1992 no Rio de Janeiro, com falantes com nível universitário de formação escolar, não só confirmamos os resultados diacrônicos como também verificamos a mesma hierarquia no preenchimento do sujeito, com referentes com o traço [+hum] liderando a mudança (Duarte 1995; 2000):

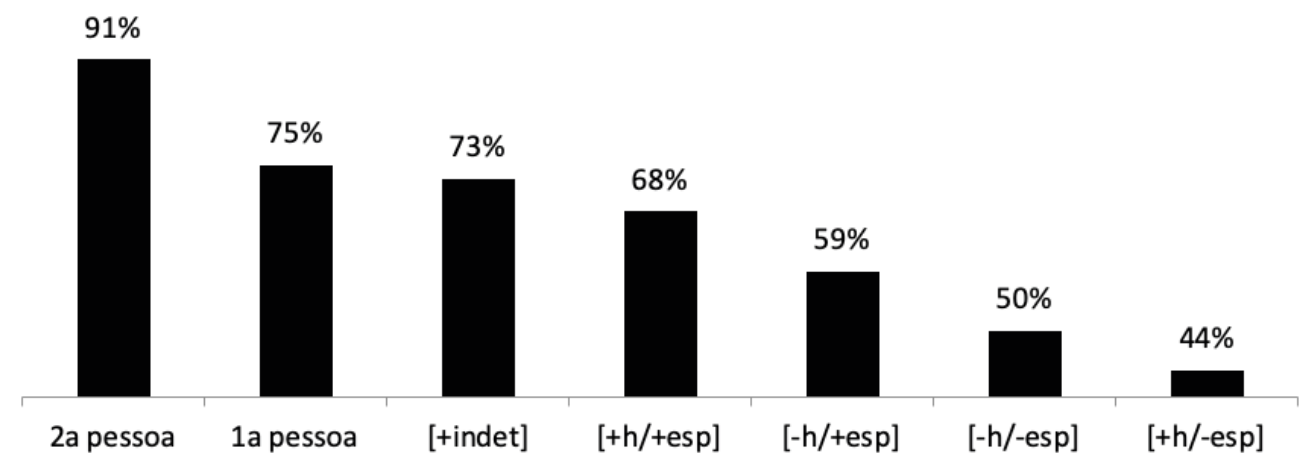

Figura 3. Sujeitos referenciais expressos (vs nulos) na fala espontânea (Amostra NURC-RJ - 1992) adaptado de Duarte (1995)

As duas seções seguintes mostrarão que a remarcação do PSN afeta, também, a ordem do sujeito em relação ao verbo. A perda do sujeito pós-verbal no PB atinge não somente a ordem VS em sentenças apresentativas, como evidenciam os resultados sobre o sujeito de verbos inacusativos, bem como a ordem em interrogativas-Q. Dessa forma, é possível considerar a produtividade do sujeito pós-verbal (não só o de sentenças apresentativas), uma característica das LSNs, como já tinham evidenciado os resultados da comparação de variedades do português e do espanhol de Soares da Silva (2011) e o estudo de Marins (2009) sobre o italiano, e concluir que a tendência à anteposição do sujeito no PB é mais um dos efeitos da mudança paramétrica em direção a uma marcação [-Sujeito Nulo].

\section{A ordem V-DP/DP-V em sentenças com verbos inacusativos: diacronia e sincronia}

Santos (2008) tinha, em seu estudo diacrônico, a hipótese de que os verbos inacusativos, por terem um DP argumento interno na função de sujeito, seriam mais resistentes à mudança em direção à anteposição. De fato, é o que mostram os resultados da 
Figura $4^{5}$. Percebe-se que as frequências da ordem DP-V, em relação a V-DP, pouco se alteram, oscilando em torno dos 55\%, e que o gráfico não exibe uma curva característica de mudança em progresso:

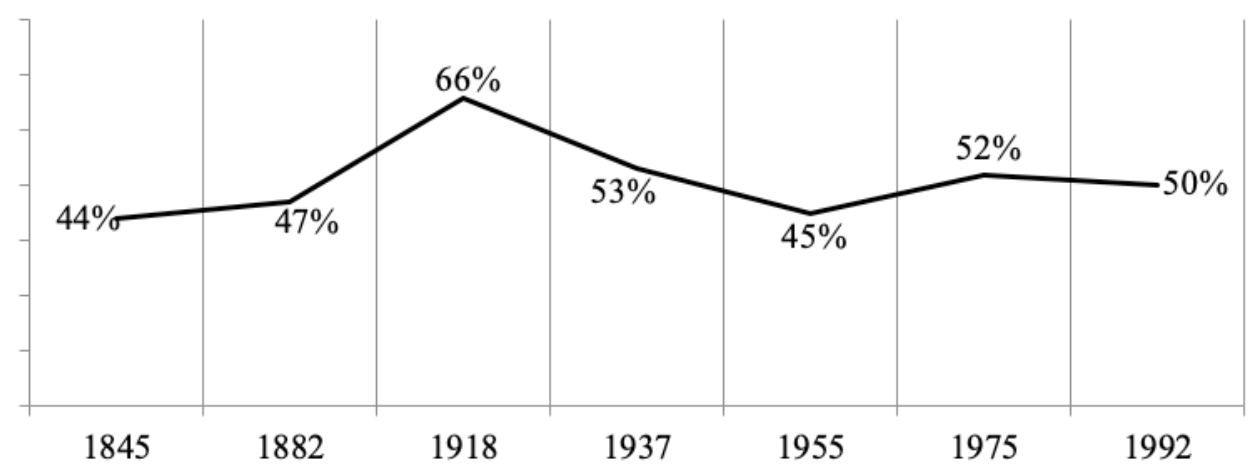

Figura 4. Frequência de DP-V com verbos inacusativos no PB - adaptado de Santos (2008)

Dos grupos de fatores selecionados como condicionadores da variação, o mais influente foi a definitude do DP, codificada como [+definido] e [-definido]. Os DPs definidos (na forma de pronome pessoal ou nome próprio, ou introduzidos por artigo definido, possessivo, demonstrativo, quantificador, ou, ainda, modificados por oração relativa), favorecem a anteposição, como se vê em (9). Os DPs indefinidos (na forma de nome comum sem determinante, ou introduzidos por artigo indefinido, pronome indefinido ou expressáo partitiva) favorecem a ordem V-DP, mostrada em (10).

(9) a. Josefina: [...] e o noivo desaparece de casa do dia para a noite.

b. Aparecida: [...] antes do meu pai morrer.

( $O$ defeito de família, França Júnior 1870)

(Pedro Mico, Zumbi do Catacumba, Antonio Callado 1954)

c. Carlos: [...] se essas dores aparecem todos os dias e a uma hora certa [...]

(Tipos da atualidade, França Júnior 1862)

d. Glicério: [...] dois tiros passaram tinindo por mim.

(Um elefante no caos, Millôr Fernandes 1955)

5. Todos os estudos com base em peças de teatro citados neste texto se baseiam no estudo pioneiro de Duarte (1993), que investigou a representação do sujeito diacronicamente, usando sete peças. Por diversos motivos, incluindo o fato de esses estudos posteriores investigarem fenômenos de ocorrência mais rara, a amostra foi ampliada, mantendo as mesmas características da amostra original, quanto ao caráter mais leve e aos sete períodos de tempo em que foram distribuídas as peças usadas por Duarte (1993). Para facilitar ao leitor a comparação dos resultados, mantivemos, nos gráficos, o ano da peça utilizada por Duarte (1993), que representa, na verdade, um conjunto de peças relativas a um período do tempo, em torno de tal ano. 
e. Dona Irene: [...] que Maria nasceu no Sul da França!

(No coração do Brasil, Miguel Falabella 1992)

(10)a. Mariquinhas: [...] Oh! mamãe, lá caiu um homem da Maxambomba [...]

(Tipos da atualidade, França Júnior 1862)

b. André Barata: [...] está me vaticinando que hoje acontece-me alguma.

( $O$ defeito de família, França Júnior 1870)

c. Ambrósio: [...] Basta um bocado de boa vontade.

(O noviço, Martins Pena 1845)

d. Zelia: Faltam-me recursos.

(O hóspede do quarto $n^{\circ}$ 2, Armando Gonzaga 1937)

Revisitando esses resultados, Santos e Soares da Silva (2012) voltaram a atenção ao grupo de fatores que separa os verbos em cinco grupos. Todos os verbos inacusativos que ocorreram nos dados foram classificados segundo semelhanças semânticas: (a) verbos de permanência de estado, (b) verbo existencial, (c) verbos de movimento, (d) verbos eventivos, e (e) verbos que, no córpus, selecionam apenas argumento [+hum]. Segue a lista de todos os verbos, por categoria, acompanhada de exemplos do grupo de verbos:

(a) ficar, restar, sobrar, faltar, bastar, importar

(11)Ficou o amor.

(Maria Cachucha, Joracy Camargo 1937)

(b) existir

(12)Beto: [...] que no Brasil não existe preconceito racial.

(Os órfäos de Jânio, Millôr Fernandes 1979)

(c) chegar, vir, entrar, cair, subir, descer, sair, partir, embarcar

(13) Yara: O seu dia chegará...

(A vida tem três andares, Humberto Cunha 1938)

(d) acontecer, ocorrer, transcorrer, suceder, começar, terminar, principiar, acabar, cessar, prevalecer, durar, reinar, aparecer, desaparecer, surgir, ressurgir, correr, circular, seguir, crescer, aumentar, diminuir, avançar, passar, falhar

(14)a. Senador: [...] aconteceu algo muito desagradável...

(A garçonnière de meu marido, Silveira Sampaio 1949)

b. Regina: E então a coisa mais engraçada aconteceu.

(A partilha, Miguel Falabella 1990) 
(e) morrer, nascer, envelhecer

(15)a. Rosa: Passado esse tempo, morreu a mamãe.

(O noviço, Martins Pena 1945)

b. Margareth: Quando meu pai morreu, eu pensei assim: agora não vou ter ninguém mais pra me escutar.

(No coração do Brasil, Miguel Falabella 1992)

A Figura 5 mostra as frequências da ordem DP-V por tipo de verbo, ao longo dos sete períodos analisados. Nos conjuntos de verbos (a), (c) e (d) ${ }^{6}$, os percentuais oscilam em torno de um eixo, apresentando uma curva não indicativa de mudança. Para o grupo de verbos de acontecer, as frequências variam em torno de 60\%; para o grupo de chegar, em torno de $50 \%$; e, no para o conjunto de verbos que contém ficar, os percentuais são em torno de $20 \%$.

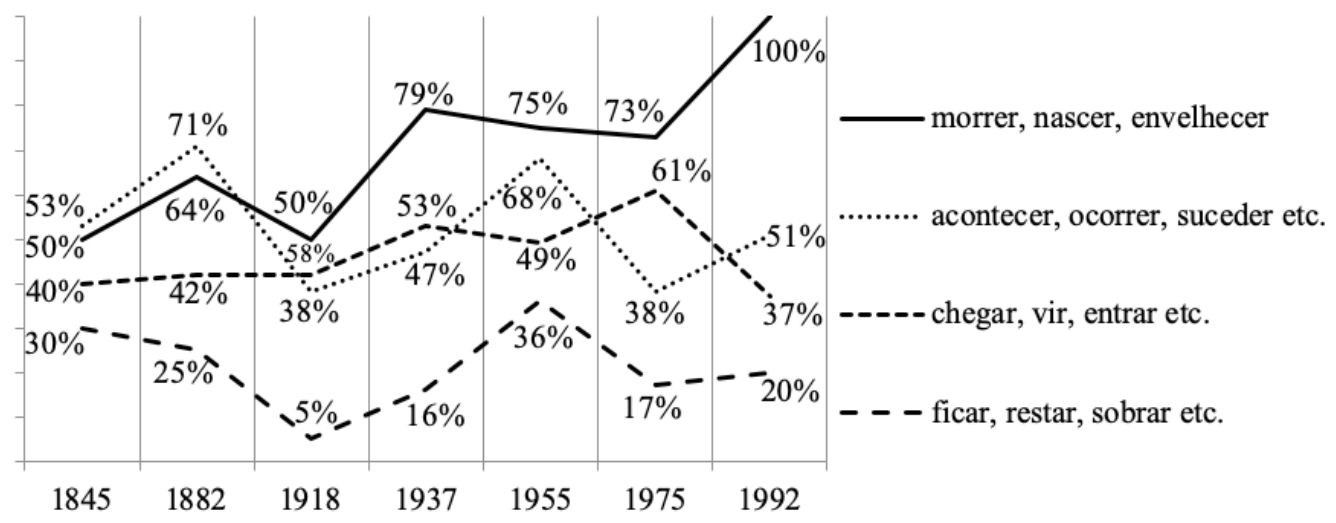

Figura 5. Sujeito anteposto por grupo de verbo inacusativo - adaptado de Santos e Soares da Silva (2012: 138)

Chama à atenção, porém, o resultado encontrado para os verbos do grupo morrer, nascer e envelhecer (representado pela linha contínua), cuja taxa de anteposição aumenta de $50 \%$, no período " 1845 " (primeira sincronia do estudo) a $100 \%$, no período "1992" (última sincronia considerada), quando nenhum dado de ordem V-DP foi encontrado associado a esses verbos. Isso mostra que a mudança em direção à ordem DP-V já se implementa nas estruturas com verbos inacusativos, afetando, inicialmente, os verbos que selecionam argumentos com o traço [+hum]. E, observando

6. Foram encontrados pouquíssimos dados do verbo existir, o único classificado na categoria (b) existencial. Por esse motivo, tais dados foram excluídos da análise desse grupo de fatores, e não figuram na tabela. 
mais detalhadamente, é possível perceber três grandes estágios da transição: nos três primeiros períodos, com percentuais entre $50 \%$ e $64 \%$; do quarto ao sexto períodos, com frequências de DP-V na casa dos 70\%; e no último período, com anteposição do sujeito categórica ${ }^{7}$, como ilustrado em (15b) e (16), para o verbo morrer.

(16)a. Selma: [...] Quando a Milena morreu, o tio Amaro já tinha morrido!

b. Laura: [...] mas o noivo de Jennifer Jones morre.

(A partilha, Miguel Falabella 1990)

Não é por coincidência que esses três estágios correspondem aos três paradigmas mostrados na Tabela 1 (Seção 1): os dois momentos de aumento mais acentuado da ordem DP-V correspondem, respectivamente, à datação da generalização do pronome você e à época da pronominalização de a gente, que passa a concorrer com nós (Lopes 2003). Curva semelhante foi encontrada nos resultados gerais para o preenchimento do sujeito referencial, por Duarte (1993). A Figura 6 mostra a evoluçáo das taxas de sujeitos plenos (Duarte 1993), representada pela linha pontilhada, junto com os percentuais de anteposição do sujeito de nascer, morrer e envelhecer, representada pela linha contínua extraída da Figura 5.

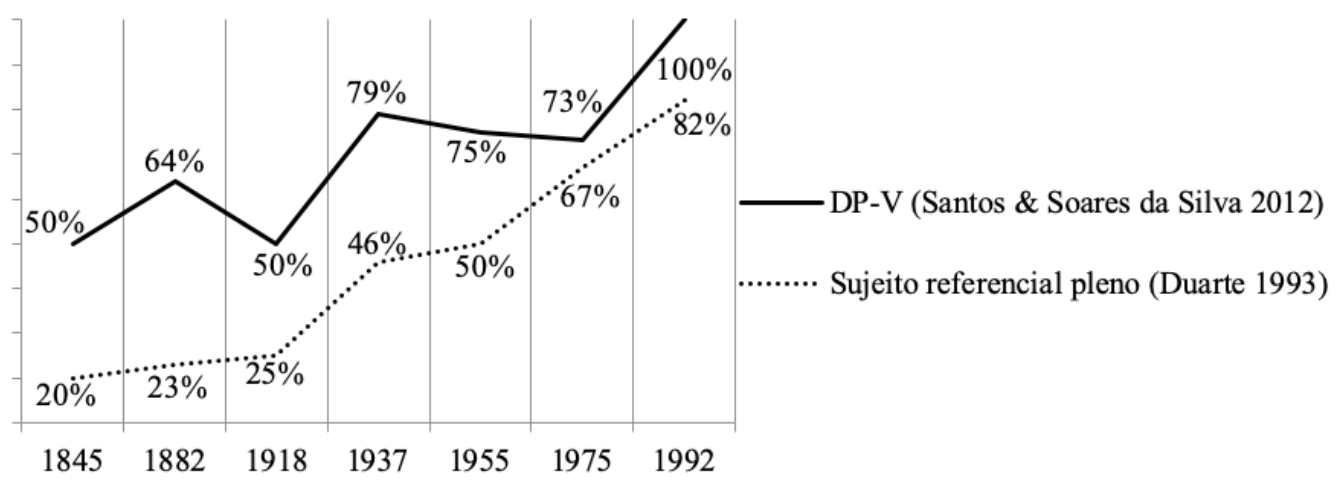

Figura 6. Sujeitos referenciais plenos e ordem DP-V (com nascer, morrer e envelhecer) em sete períodos

Note-se que, para ambos os fenômenos, se observa estabilidade até o primeiro

7. O resultado categórico aqui apresentado não deve ser interpretado como uma prova de que a posposição do sujeito com esses verbos esteja ausente na gramática dos falantes; o que se pretende demonstrar é o indício de que a mudança em direção à anteposição com inacusativos já começa a se implementar com esse grupo de verbos. Em estudo sobre a fala da década de 2000, Felix (2017) confirmou que são esses os verbos que favorecem e impulsionam a anteposição, apresentando a maior taxa: 91\%, que não é categórica. Esse e outros estudos sobre a fala apresentam resultados muito semelhantes aos encontrados para a última sincronia do estudo diacrônico com peças sobre o respectivo fenômeno, o que tomamos como argumento em favor do uso de peças de teatro para estudos sincrônicos que incluam épocas para as quais não há fala gravada. 
quartel do século 20, seguida de um aumento nas frequências e novo período de estabilidade e, por fim, mais um aumento acentuado, levando às maiores taxas, observadas no último quartel do século 20. As duas linhas correm quase paralelas, e as diferenças nas taxas de aumento das frequências podem ser explicadas pelas diferenças nas características das amostras e pela natureza dos fenômenos ${ }^{8}$. Assim, os resultados para o preenchimento do sujeito referencial, postos em comparaçáo com os resultados para a anteposição do argumento dos verbos inacusativos morrer, nascer e envelhecer, são importante evidência de que sujeito nulo e sujeito posposto (e não somente em sentenças apresentativas) são propriedades do PSN, e de que a remarcação do PSN no PB é uma mudança encaixada em outra, que reorganizou os paradigmas pronominal e de flexão verbal.

A análise da fala espontânea em entrevistas sociolinguísticas apresenta resultados semelhantes às análises diacrônicas (Fernandes, Duarte \& Soares da Silva 2015), com uma competição entre V-DP e DP-V. Em estudo sincrônico, a partir de sites de reclamaçáo postadas na internet, Fernandes, Duarte e Soares da Silva (2015) atestam o avanço da preferência pelo preenchimento da posição à esquerda do verbo inacusativo. Nos dados em que o argumento selecionado pelo verbo inacusativo é um DP lexical simples ${ }^{9}$, como em (17), a anteposição alcança $72 \%$ das ocorrências, como ilustra o gráfico à esquerda da Figura 7. Quando o DP contém um adjunto que pode ser expresso sob a forma de um DP genitivo com relação semântica de posse (18a), a posposição é de apenas 4\%; além da anteposição do argumento (18b), que alcança $38 \%$, surge outra estratégia - inicialmente notada por Pontes (1987) -, que é a preferida, conforme o gráfico da direita: o alçamento do genitivo à posição de sujeito, como em (18c), com 58\% de ocorrências.

8. Mesmo em línguas [+Sujeito Nulo], em que a posposição do sujeito é produtiva, o apagamento de um sujeito "dado", ou seja, em sentenças expressando juízo categórico, é sempre mais frequente, conforme mostrado por Soares da Silva (2011), que comparou sete variedades do português e do espanhol. Isso explica por que os percentuais de sujeitos antepostos da Figura 4 sáo mais altos do que os de sujeitos plenos, em todas as sincronias. Quanto às amostras, Duarte (1993) coletou muito mais dados do que Santos (2008), ao passo que Santos os coletou de 23 peças, acrescentando mais 16 às sete utilizadas por Duarte (1993).

9. A anteposição do argumento é categórica quando este é um pronome, ou seja, um elemento "dado": "Comprei [uma geladeira $]_{\mathrm{i}}$ de quase $5 \mathrm{MIL}$ reais e em menos de um ano, ela quebrou 3 vezes". 

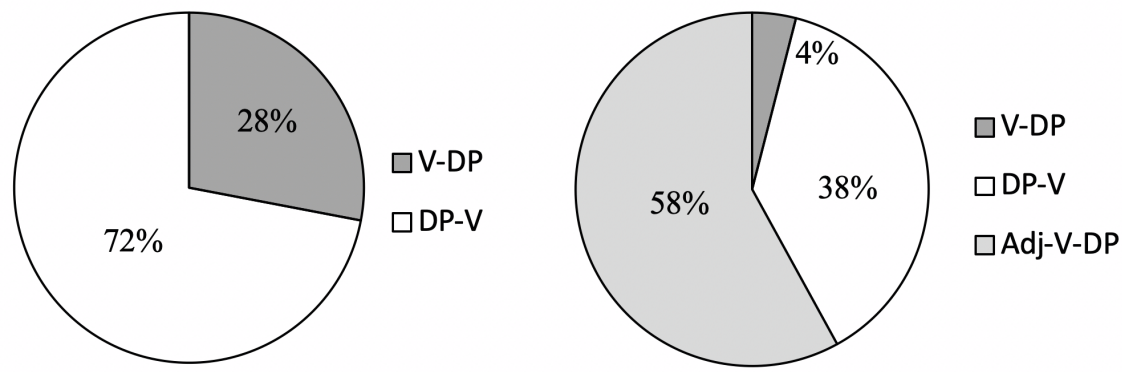

Figura 7. Ordem V-DP/DP-V e alçamento de adjunto no PB - adaptado de Duarte e Fernandes (2016)

(17)a. Terminou o curso.

b. $O$ curso terminou.

(18)a. Soltou [a porta da minha geladeira].

b. [A porta da minha geladeira] soltou.

c. A minha geladeira ${ }_{\mathrm{i}}$ soltou [a porta $\left.\mathrm{t}_{\mathrm{i}}\right]^{10}$

\section{As sentenças interrogativas: evidências diacrônicas e sincrônicas do preenchimento e da ordem}

A análise de Pinheiro e Marins (2012) ampliou a de Duarte (1992) para as interrogativas-Q nas peças de teatro. Enquanto a análise de Duarte incluía apenas as estruturas com sujeito expresso, a fim de observar a competição VS / SV, Pinheiro e Marins incluíram as ocorrências sujeito nulo (19a) e das ordens Q VS, exemplificada em (19b), e Q SV, em (19c). Nos três primeiros períodos considerados, os percentuais pouco se alteram, exatamente como foi observado nos outros estudos diacrônicos, apresentados nas seçóes 1 e 2 . Como esperado para uma língua de sujeito nulo, o apagamento do sujeito dêitico ou um DP dado no contexto discursivo, era a opçáo preferida até o primeiro quartel do século 20, com percentuais entre $59 \%$ e $58 \%$, seguido da ordem VS, com percentuais entre $41 \%$ e $43 \%$, sendo a ordem SV muito rara, com percentuais que não chegam a 10\% nas três primeiras sincronias, conforme a Figura 8.

10. Náo se deve confundir o tipo de estrutura em (18c) com casos de elemento deslocado para uma posição periférica da sentença. Em (18c), como nos exemplos (i) e (ii), o genitivo de um DP (não agentivo) selecionado por um verbo inacusativo é alçado para Spec,TP, como comprovam ocorrências com a concordância verbal:

(i) Fazia tanto calor que $\varnothing_{\text {expl }}$ rachou [a pele das minhas pernas]

(ii) Fazia tanto calor que [as minhas pernas $]_{i}$ racharam [a pele $\mathrm{t}_{\mathrm{i}}$ ]

Com um elemento deslocado, teríamos:

(iii) ....as minhas pernas $\varnothing_{\text {expl }}$ rachou a pele. 
(19)a. Como $\varnothing_{2 \mathrm{ps}}$ apanhou esse reumatismo?

b. Que te importas tu com o canudo?

(O simpático Jeremias, Gastão Tojeiro 1918)

c. O que é que tu tens na barriga?

(Caiu o ministério, França Júnior 1889)

(Caiu o ministério, França Júnior 1889)

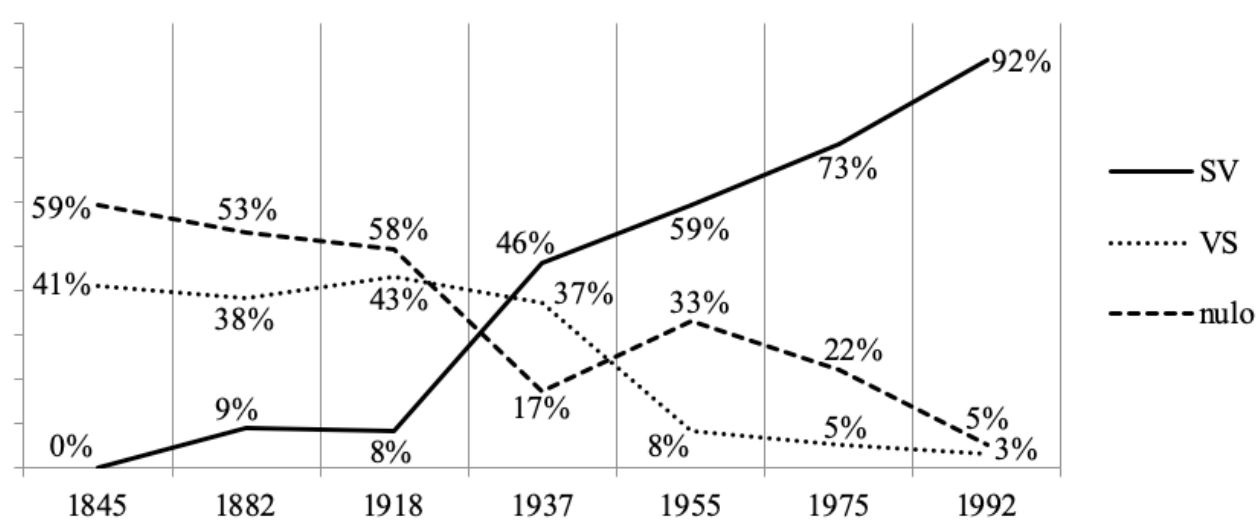

Figura 8. Distribuição da ordem nas interrogativas-Q no PB (Paula 2016) - adaptado de Pinheiro e Marins (2012)

Semelhantemente aos estudos sobre o preenchimento do sujeito referencial e a anteposição do sujeito de verbos inacusativos, no contexto das interrogativas os percentuais começam a se alterar significantemente a partir dos anos 1930 . O sujeito nulo e a ordem VS gradativamente perdem espaço, chegando, na última sincronia analisada, a apenas 5\% e 3\% de ocorrências, respectivamente. A ordem SV, por outro lado, segue uma linha ascendente e chega a alcançar a quase totalidade dos dados no período de "1992", quando alcança 92\%.

A ordem SV não ocorreu no primeiro período analisado (1845). Nos períodos “1882" e "1918", as ocorrências de SV são raras, e todas elas estáo associadas a sentenças com a clivagem é que, como em (19c) acima - ainda pouco frequentes até o terceiro período. A partir do período "1937”, segundo Duarte (1992) e Paula (2016), a clivagem passa a ser mais produtiva e isso teria desencadeado o aumento da ordem SV, como mostram os exemplos em (20). A partir do período "1955", essa ordem passa a independer da ocorrência de clivagem, que se torna opcional, conforme os exemplos em (21).

(20)a. Onde é que eu meti essa chave?

(Um elefante no caos, Millôr Fernandes 1955) 
b. Como é que a senhora sabe dessa história toda, se era só uma foto?

(No coração do Brasil, Miguel Falabella 1992)

(21)a. E o que você quer?

b. Por que você não vem?

(A mulher integral, Carlos Eduardo Novaes 1975)

As estruturas clivadas continuam no sistema e as "clivadas reduzidas" só aparecem a partir do período "1975", permanecendo até a última sincronia do estudo. Tais dados exibem somente a ordem SV, como mostra (22):

(22)a. Que que eu vou dizer a ele?

(A mulher integral, Carlos Eduardo Novaes 1975)

b. Por que que prá você, a bala tem sempre que acertar no mocinho?

(No coração do Brasil, Miguel Falabella 1992)

Nas duas últimas sincronias, a ordem VS, praticamente extinta, só é atestada com verbos incusativos, desde que o sujeito seja um DP lexical:

(23)a. Como é que me acontece uma coisa dessas?

b. Onde andará a Neiva?

(A mulher integral, Carlos Eduardo Novaes 1975)

(No coração do Brasil, Miguel Falabella 1992)

Para obter uma comparação com dados sincrônicos, Paula (2016) levantou todas as interrogativas $\mathrm{Q}$ produzidas por documentadores brasileiros em recente amostra gravada no Rio de Janeiro ${ }^{11}$, confirmando (a) a quase ausência de Q VS e de sujeitos nulos (4\% no total), (b) a preferência por Q SV tanto com clivagem (44\%) quanto sem a clivagem (42\%), e (c) a presença de interrogativas com Q in situ (10\%).

\section{O alçamento a partir de uma oração subordinada: estudos diacrônicos e sincrônicos}

Henriques (2012) investigou, também usando a mesma amostra de peças de teatro brasileiras, as estruturas em que um verbo seleciona um argumento interno em forma de oração subordinada e não seleciona argumento externo, permitindo que o

11. Amostra do projeto Estudo comparado dos padróes de concordância em variedades africanas, brasileiras e europeias, hospedada no site www.concordancia.letras.ufrj.br, organizado por Silvia Rodrigues Vieira (Universidade Federal do Rio de Janeiro) e Maria Antonia Mota (Centro de Linguística da Universidade de Lisboa). 
sujeito da subordinada seja alçado para preencher a posição estrutural de sujeito da oração raiz. Os verbos encontrados foram separados em duas categorias, a depender da forma da oração subordinada selecionada: há verbos que têm como argumento interno uma subordinada infinitiva (InfP) e o verbo parecer, que pode selecionar, como argumento interno, tanto um InfP quanto uma subordinada finita $(\mathrm{CP})$. A variável relacionada ao verbo parecer contém três possíveis realizaçóes, explicitadas a seguir.

(a) Em (24), o complemento do verbo parecer é um CP. Na realização sem alçamento, náo há movimento do sujeito da oraçáo subordinada:

$(24) \varnothing_{\text {expl }}$ Parece $\left[{ }_{C P}\right.$ que vocês não pensam na vida $]$.

(b) Se o complemento de parecer for um InfP, não há flexão atribuidora de Caso ao sujeito da oração subordinada. Nesse contexto, o alçamento do sujeito da subordinada é obrigatório, como em (25), já que, na posição de sujeito do verbo parecer, flexionado, ocorrerá atribuição de nominativo. Essa estrutura, denominada alçamento padrão, ocorre inclusive em línguas de sujeito nulo, como o português europeu.

(25) Vocês parecem [ ${ }_{\text {InfP }} t_{i}$ não pensar na vida ].

(c) A inovação do PB é a estrutura em (26). Entre diversas possibilidades de análise propostas, pode ser analisada como um alçamento de tópico (Martins \& Nunes $2010)^{12}$. O complemento de parecer é uma oração que contém flexão, portanto não há necessidade de movimento do sujeito da oração subordinada em "busca" de Caso - por esse motivo, tal realização não é encontrada em línguas de sujeito nulo, como o português europeu.

(26)a. Nilson: Vocês ${ }_{i}$ parecem $\left[{ }_{\mathrm{CP}}\left[{ }_{\mathrm{TopP}} \mathrm{t}_{\mathrm{i}}\left[{ }_{\mathrm{IP}}\right.\right.\right.$ que $\varnothing_{\mathrm{i}}$ náo pensam na vida $\left.\left.]\right]\right]$.

(No coração do Brasil, Miguel Falabella 1992)

b. Vocês parecem $\left[{ }_{\mathrm{CP}}\left[_{\mathrm{TopP}} \mathrm{t}_{\mathrm{i}}\left[_{\mathrm{IP}}\right.\right.\right.$ que vocês não pensam na vida $\left.\left.]\right]\right]$.

O constituinte que se move é o tópico da oração subordinada, correferente ao seu sujeito, para ocupar a posiçáo de sujeito na raiz parecer. O sujeito da oraçáo subordinada pode ser nulo, como em (26a), encontrado no córpus, ou expresso, como em (26b), realizado foneticamente numa das representaçóes da peça no teatro. Trata-se de uma estratégia inovadora do PB para evitar um expletivo nulo (preenchimento da

12. Outra possibilidade de análise é a que considera essa realização um "hiperalçamento" (Ferreira 2000). O sujeito da oração subordinada é movido, como no alçamento padrão, segundo o autor pelo fato de $\mathrm{T}$ da encaixada ser defectivo para checar Caso nominativo. Esse movimento pode deixar, na posição de origem, um vestígio não pronunciado, como em (26a), ou um pronome cópia, como em (26b), e ambos desencadeiam concordância no verbo da oração subordinada. 
posição de sujeito do verbo parecer), consequência da mudança de [+Sujeito Nulo] para [-Sujeito Nulo].

A interpretação do gráfico da Figura 9 revela fatos interessantes. Na primeira sincronia, a estrutura sem alçamento estava presente em todos os dados com parecer, mas logo começa a sofrer uma redução gradual, até o período "1937", quando chega a 40\% dos dados. Nesse mesmo intervalo, tal realização parece ser substituída pela estrutura com alçamento padrão, que, totalmente ausente no período " 1845 ", se faz cada vez mais presente, atingindo, também, $40 \%$ na quarta sincronia, da qual foi coletado o exemplo (27).

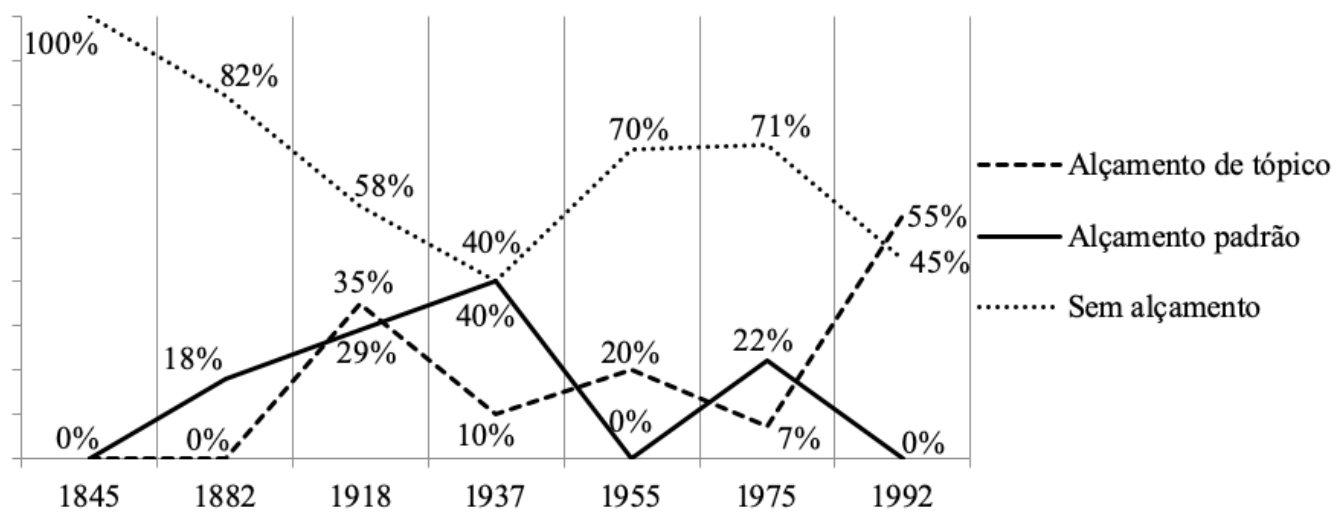

Figura 9. Estruturas de alçamento com o verbo parecer através do tempo - adaptado de Henriques (2012)

(27) Elisa: [...] Ela $a_{\mathrm{i}}$ parece [ $\mathrm{t}_{\mathrm{i}}$ ter o diabo no corpo].

(O simpático Jeremias, Gastão Tojeiro 1918)

Tal variação, nessas três primeiras sincronias, porém, não parece estar relacionada à remarcação do PSN. Trata-se da possibilidade de o argumento interno de parecer ser representado por um InfP, que passa a competir com um CP, única possibilidade na primeira sincronia. $\mathrm{O}$ alçamento do sujeito é motivado por necessidade de atribuição de Caso e, como já dito, não é exclusividade de línguas que tendem a preencher a posição de sujeito.

É a partir do período "1937", o mesmo em que se detecta o gatilho das outras mudanças citadas aqui, nas seçóes anteriores, que os resultados se invertem. O alçamento padrão passa a perder espaço nas três últimas sincronias do estudo. E a estrutura sem alçamento, exemplificada em (28), volta a ser a preferida, atingindo $70 \%$ e $71 \%$ dos dados nos períodos " 1955 " e "1975".

(28)Médico: Ninguém responde. $\varnothing_{\text {expl }}$ Parece [ que a cidade inteira morreu ].

(Do tamanho de um defunto, Millôr Fernandes 1955) 
Ao mesmo tempo, observa-se a evolução das frequências da estrutura com alçamento de tópico. Ausente nas duas primeiras sincronias, passa a fazer-se presente nos quatro períodos seguintes, com frequências em torno de $20 \%$ e, no último período do estudo, tem a produtividade aumentada bem mais acentuadamente, chegando a ser a variante preferida. A curva tracejada, que representa as frequências de alçamento de tópico na Figura 9, é compatível com a transição descrita para a mudança sofrida pelos fenômenos descritos nas seçóes anteriores, com dois momentos de aumento mais acentuado de frequência, relacionados a dois momentos de mudança no quadro pronominal e no paradigma verbal.

Além de parecer, também foi investigado o alçamento com outros verbos: acabar, bastar, convir, custar, demorar, faltar e levar (Henriques 2013). Tais verbos podem selecionar, como argumento interno, uma oraçáo finita e/ou uma oração não finita. Porém, diferentemente do que ocorre com parecer, nestes outros casos a oração subordinada apresenta o infinitivo flexionado e, sendo a flexão capaz de atribuir Caso nominativo ao sujeito, o alçamento é variável, conforme os exemplos de Henriques (2013):

(29)a. $\varnothing_{\text {expl }}$ Levou uma hora [ para os meninos terminarem o trabalho ].

b. $\varnothing_{\text {expl }}$ Demorou uma hora [ para os meninos terminarem o trabalho ].

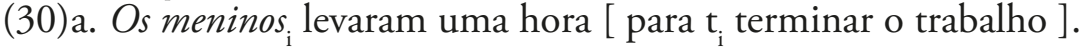

b. [ Os meninos demoraram uma hora [ para $\mathrm{t}_{\mathrm{i}}$ terminar o trabalho ].

Esses verbos foram analisados separadamente de parecer, porque só são possíveis duas realizaçóes: com e sem alçamento. Por outro lado, por terem sido encontrados poucos dados para cada um dos verbos, eles foram tratados em conjunto, em uma única análise. A Figura 10 ilustra a evolução das frequências de alçamento com os verbos acabar, bastar, convir, custar, demorar, faltar e levar:

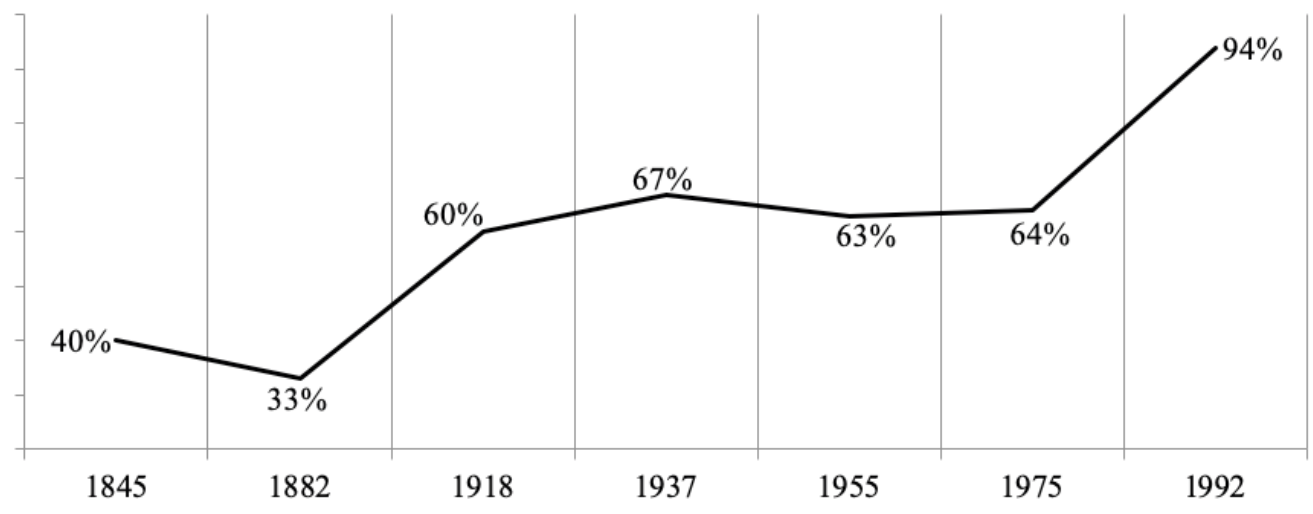

Figura 10. Alçamento com acabar, bastar, convir, custar, demorar, faltar e levar (Henriques 2013) 
$\mathrm{Na}$ primeira sincronia, a realização da estrutura sem alçamento era a preferida, sendo de apenas $40 \%$ a frequência de dados com alçamento. O gráfico revela um primeiro aumento significativo, que leva os percentuais de alçamento à casa do $60 \% \mathrm{du}$ rante quatro períodos da análise, e um segundo, que faz as ocorrências de alçamento, no último período, atingirem a quase totalidade dos dados, o que revela uma curva de mudança muito semelhante às dos outros resultados que aqui citamos. Seguem exemplos sem alçamento e com alçamento, retirados do córpus, com o predicador de alçamento demorar:

(31)a. Nilson: Acho que $\varnothing_{\text {expl }}$ demorou mais de um mês [ pra pobre da Helene conseguir botar o moleque no mundo ].

(No coração do Brasil, Miguel Falabella 1992)

b. Selma: $E u_{\mathrm{i}}$ não demorei tanto tempo [ pra $t_{\mathrm{i}}$ buscar auxílio médico ].

(A partilha, Miguel Falabella 1990)

Resultados para a fala espontânea de entrevistas sociolinguísticas (Henriques \& Duarte 2006; Duarte 2007) revelam, em relação ao verbo parecer, forte competição entre a construção sem alçamento $(42 \%)$ e com alçamento de tópico ${ }^{13}(44 \%)$ (ex. 32 ), ficando as demais possibilidades com apenas 14\%. Mais avançado, porém, é o alçamento com os demais verbos que, além de preferir um argumento oracional no infinitivo, revelam ampla preferência pelo alçamento, que já alcança percentuais acima de $80 \%$ :

(32)a. $\varnothing_{\text {expl }}$ Parece que ela não é muito humilde

b. Ele $e_{\mathrm{i}}$ parece que (ele $)_{\mathrm{i}}$ sofreu muito quando era pequeno, quando era criança

(33)a. $\varnothing_{\text {expl }}$ Só faltava agora eles dizerem que não era culpa deles. (PEUL 2000)

b. Eles $s_{\mathrm{i}}$ ainda faltavam [ $t_{\mathrm{i}}$ receber o dinheiro do patrão ]. (PEUL 1980)

13. Não desconhecemos as propostas de Martins e Nunes $(2005 ; 2010)$, que distinguem o hiperalçamento e o alçamento de tópico (ou hiperalçamento aparente), o primeiro, com o sujeito alçado para Spec,TP da matriz, por conta de T da encaixada ser defectivo para checar Caso e o segundo, um alçamento de um tópico, retomado por um pronome fraco na encaixada. Nossas análises revelam que ainda é possível ter um pronome nulo em variaçáo com um pronome fraco expresso na encaixada. daí nossa opção pelo alçamento de tópico para as duas estruturas. O que está alçado é para Henriques (2012) um tópico, seja o sujeito da encaixada um pronome nulo ou expresso, uma decisão em consonância com a possibilidade de ainda termos sujeitos referenciais nulos em variação com expressos, particularmente na $3 .^{\mathrm{a}}$ pessoa. 


\section{Conclusão}

Com base na Sociolinguística Variacionista e no quadro de Princípios e Parâmetros da Gramática Gerativa, apresentamos resultados de estudos sobre a realização de diferentes fenômenos no PB. Todos eles estariam, de alguma maneira, relacionados a uma das propriedades que caracterizam uma língua [+Sujeito Nulo]. A comparação desses resultados mostra que a mudança observada para todos esses fenômenos se implementa de maneira muito semelhante, o que sustenta que todas essas propriedades são afetadas pela mudança na marcação do valor do PSN no PB.

Os estudos diacrônicos foram realizados com base em dados coletados das falas de peças de teatro popular do Rio de Janeiro, escritas ao longo dos séculos 19 e 20, que foram metodologicamente distribuídas em sete períodos. Estudos com base na fala de entrevistas sociolinguísticas gravadas no final do século 20, período correspondente à última sincronia dos estudos diacrônicos (anos 1990), e em um gênero de escrita menos monitorada apresentam resultados semelhantes aos encontrados para a última sincronia dos estudos diacrônicos correspondentes. Esse fato ajuda a sustentar que, nas falas das peças de teatro de caráter mais popular, a busca de aproximação do uso da língua por parte dos falantes é bem sucedida, sendo esse, certamente, o córpus mais aproximado da fala a que se deve recorrer para investigaçóes linguísticas sobre períodos passados, quando ainda não havia sido inventado o gravador de voz.

Duarte (1993), em estudo diacrônico com dados de peças teatrais, já havia mostrado que, quanto ao preenchimento do sujeito, a curva de frequências ao longo do período analisado pode ser dividida em três fases de transição: do século 19 até o primeiro quartel do século 20, a preferência é pelo sujeito nulo e as taxas de preenchimento se mantêm estáveis; a partir dos anos 1930, há um aumento significativo na produtividade do sujeito preenchido, que volta à estabilidade; no último quartel do século 20, observa-se outro aumento significativo nos percentuais. A autora mostra que essas três fases correspondem a alteraçôes no paradigma flexional do verbo, que sofre reduções e neutralizaçóes. A redução do paradigma flexional, por sua vez, é consequência da entrada de você(s) e a gente no quadro pronominal, que, não por coincidência, correspondem, respectivamente, à época do primeiro e do segundo aumento mais acentuado na frequência de sujeitos expressos.

Ao comparar esse resultado com os de outros estudos diacrônicos, como os que tratam da mudança em direção à anteposição do argumento de verbos inacusativos e o sujeito em oraçóes interrogativas Q, e da crescente tendência a preencher a posição de sujeito de um verbo que não seleciona argumento externo, por meio de alçamento (do sujeito da oração subordinada, quando esta é o argumento interno, ou de um adjunto pertencente ao DP argumento interno), é possível notar a existência dos dois momentos de mudança mais acentuada em todos eles, que apresentam gráficos com curvas muito semelhantes. Não há como negar que todas essas mudanças, na verdade, 
são uma só. Concluímos, pois, que se trata de uma mudança na marcação do PSN no $\mathrm{PB}$, que passa de [+Sujeito Nulo] a [-Sujeito Nulo], mudança essa que, como prevê a teoria, tem efeito em todas as propriedades do parâmetro.

Por fim, ressaltamos que, em todos os estudos citados, não foi encontrado um único contexto estrutural em que o sujeito nulo (referencial ou expletivo) ou o sujeito pós-verbal seja categórico. Ao contrário, há, nas análises sincrônicas, bem como nas análises da última sincronia dos estudos diacrônicos, diversos contextos em que o preenchimento do sujeito é mais frequente do que o seu apagamento. E foi detectado, inclusive, um contexto em que a anteposição é categórica: não foram encontrados dados de ordem VS com verbos inacusativos com o sujeito em forma de pronome pessoal. O Finlandês parece ser um sistema estável, que pode exibir sujeitos nulos de $3 .{ }^{a}$ pessoa em encaixadas, desde que controlados pelo sujeito da matriz. Não é o caso do $\mathrm{PB}$, que ainda exibe, em índices cada vez mais baixos, sujeitos nulos de 1 . $^{\mathrm{a}} 2 \mathrm{a}^{\mathrm{a}} \mathrm{e}$ $3 .^{\text {a }}$ pessoas. Isso não se compara a um sistema de sujeito nulo parcial "estável", como parece ser o Finlandês. Em outras palavras, o PB revela um processo de mudança em progresso, não pode ser comparado às línguas reunidas sob o rótulo de LSNs parcial. Resultados recentes (Duarte 2019) comparando o português europeu e o PB com base em amostras gravadas no ano 2010, disponíveis em: http://corporaport.letras. ufrj.br/ revelam que os índices de sujeitos nulos referenciais, ainda atestados em todos os padrões (exemplos em 4a,b,c,d), são ainda mais baixos do que os encontrados

Um outro argumento apresentado por Holmberg, Nayudu e Sheehan (2009), Holmberg (2010), Holmberg e Phimsawat (2017), entre outros, para a inclusão do português brasileiro entre as línguas de sujeito nulo parcial seria e existência de um nulo genérico (exclusivo ou inclusivo). Mais recentemente, Marins, Soares da Silva e Duarte (2017), mostram que o nulo exclusivo está em competição com o "eles" indeterminado, e o nulo inclusivo, em competição com "você" e "tu", com ampla preferência pelas formas nominativas. Para aceitar tal proposta, seria necessário atestar contextos de ocorrência do sujeito nulo que não sejam afetados pela mudança - o que não existe (Kato \& Duarte 2014). O que o estudo revela ainda é como se dá o efeito da remarcação do valor do PSN sobre as sentenças impessoais: o PB não desenvolveu um expletivo lexical - que o Finlandês usa em variação com adjuntos para evitar um verbo em primeira posição - mas lança mão de operações de alçamento para a posição estrutural de sujeito "disponível", preenchendo-a com elementos referenciais (nota 1) o que está em consonância com a proeminência de tópico que o sistema revela: línguas orientadas para o discurso náo desenvolvem elementos lexicais sem referência. Como a mudança exige a satisfaçáo do EPP, elementos referenciais alçados para Spect, TP passam a ser licenciados.

O que apresentamos aqui é uma análise empírica, que não pode ser comparada com dados de intuição. Até o momento, o que podemos afirmar sobre o PB é que estamos testemunhando uma mudança em curso e observando seus efeitos colaterais, o que pode contribuir para os estudos relacionados ao Parâmetro do Sujeito Nulo. 


\section{Referências do córpus diacrônico}

(a) Período “1845”

Macedo, Joaquim M. de. 1860. Luxo e vaidade. Sociedade Brasileira dos Autores Teatrais.

Martins Pena, Luiz C. 1833. O juiz de paz na roça. En As melhores comédias de Martins Pena. 9-28. Porto Alegre: Mercado Aberto, 1987.

Martins Pena, Luiz C. 1833-1837. Um sertanejo na corte. Sociedade Brasileira dos Autores Teatrais.

Martins Pena, Luiz C. 1844. O judas em sábado de Aleluia. En As melhores comédias de Martins Pena. 151-176. Porto Alegre: Mercado Aberto, 1987.

Martins Pena, Luiz C. 1844. Os irmãos das almas. Sociedade Brasileira dos Autores Teatrais.

Martins Pena, Luiz C. 1845. O cigano. Sociedade Brasileira dos Autores Teatrais.

Martins Pena, Luiz C. 1845. O noviço. En As melhores comédias de Martins Pena. 73-118. Porto Alegre: Mercado Aberto, 1987.

Martins Pena, Luiz C. 1845. Os dois ou o inglês maquinista. En As melhores comédias de Martins Pena. Porto Alegre: Mercado Aberto, 1987.

Martins Pena, Luiz C. 1845. Quem casa quer casa. En As melhores comédias de Martins Pena. 177-196. Porto Alegre: Mercado Aberto, 1987.

\section{(b) Período “1882”}

França Júnior, Joaquim J. 1862. Tipos da atualidade. En Edwaldo Cafezeiro (ed.), Teatro de França Júnior. Tomo II, 19-59. Rio de Janeiro: Serviço Nacional de Teatro/Fundação da Arte, 1980.

França Júnior, Joaquim J. 1870. Defeito de família. Sociedade Brasileira dos Autores Teatrais.

França Júnior, Joaquim J.1870. Direito por linhas tortas. En Edwaldo Cafezeiro (ed.), Teatro de França Júnior. Tomo II, 61-121. Rio de Janeiro: Serviço Nacional de Teatro/Fundação da Arte, 1980.

França Júnior, Joaquim J. 1882. Como se fazia um deputado. En Edwaldo Cafezeiro (ed.), Teatro de França Júnior. Tomo II, 123-168. Rio de Janeiro: Serviço Nacional de Teatro/Fundaçăo da Arte, 1980.

França Júnior, Joaquim J. 1883. Caiu o ministério en Edwaldo Cafezeiro (ed.), Teatro de França Júnior. Tomo II, 169-221. Rio de Janeiro: Serviço Nacional de Teatro/Fundação da Arte, 1980.

França Júnior, Joaquim J. 1883. As doutoras. En Edwaldo Cafezeiro (ed.), Teatro de França Júnior. Tomo II, 223-191. Rio de Janeiro: Serviço Nacional de Teatro/Fundação da Arte, 1980.

\section{(c) Período "1918”}

Gonzaga, Armando. 1922. A flor dos maridos. Sociedade Brasileira dos Autores Teatrais.

Tojeiro, Gastão. 1918. O simpático Jeremias. Sociedade Brasileira dos Autores Teatrais.

Tojeiro, Gastão. 1919. As "fans" de Roberto Taylor. Sociedade Brasileira dos Autores Teatrais.

Tojeiro, Gastão. 1920. A inquilina de Botafogo. Sociedade Brasileira dos Autores Teatrais. 
Tojeiro, Gastão. 1920. Onde canta o sabiá. Sociedade Brasileira dos Autores Teatrais.

\section{(d) Período “1937”}

Camargo, Joracy. 1937. Maria Cachucha. Biblioteca da Uni-Rio.

Cunha, Humberto. 1938. A vida tem três andares. Sociedade Brasileira dos Autores Teatrais.

Gonzaga, Armando. 1933. A patroa. Sociedade Brasileira dos Autores Teatrais.

Gonzaga, Armando. 1933. O troféu. Sociedade Brasileira dos Autores Teatrais.

Gonzaga, Armando. 1937. O hóspede do quarto n. ${ }^{\circ}$ 2. Sociedade Brasileira dos Autores Teatrais.

\section{(e) Período “1955”}

Callado, Antônio. 1954. O colar de coral. Sociedade Brasileira dos Autores Teatrais.

Callado, Antônio. 1954. Pedro Mico, Zumbi do Catacumba. Sociedade Brasileira dos Autores Teatrais.

Fernandes, Millôr. 1955. Bonito como um deus. En Teatro de Millôr Fernandes. 173-204. Rio de Janeiro: Civilização Brasileira, 1957.

Fernandes, Millôr. 1955. A gaivota. En Teatro de Millôr Fernandes. 205-221. Rio de Janeiro: Civilização Brasileira, 1957.

Fernandes, Millôr. 1955. Do tamanho de um defunto. En Teatro de Millôr Fernandes. 107-173. Rio de Janeiro: Civilização Brasileira, 1957.

Fernandes, Millôr. 1955. Um elefante no caos. Porto Alegre: LPM, 1979.

Fernandes, Millôr. 1955. Uma mulher em três atos. En Teatro de Millôr Fernandes. Rio de Janeiro: Civilização Brasileira, 1957.

Fernandes, Millôr. 1963. Um elefante no caos. Porto Alegre: LPM, 2001.

Muniz, Lauro César. 1963. O santo milagroso. Sociedade Brasileira dos Autores Teatrais.

Sampaio, Silveira. 1949. A garçonnière do meu marido. Sociedade Brasileira dos Autores Teatrais.

Sampaio, Silveira. 1951. Flagrantes do Rio. Sociedade Brasileira dos Autores Teatrais.

\section{(f) Período “1975”}

Fernandes, Millôr. 1979. Os órfãos de Jânio. Porto Alegre: LPM, 1979.

Neves, João das. 1976. O último carro ou as 14 estaçôes. Sociedade Brasileira dos Autores Teatrais.

Novaes, Carlos Eduardo. 1975. A mulher integral. Biblioteca da Uni-Rio.

Novaes, Carlos Eduardo. 1986. Confidências de um espermatozoide careca. Rio de Janeiro: Nórdica.

Viana, Oduvaldo. 1974. Rasga coração. Sociedade Brasileira dos Autores Teatrais. 


\section{(g) Período "1992"}

Falabella, Miguel. 1988. Sereias da Zona Sul. Sociedade Brasileira dos Autores Teatrais.

Falabella, Miguel. 1990. A partilha. Sociedade Brasileira dos Autores Teatrais.

Falabella, Miguel. 1992. Como encher um biquini selvagem. Sociedade Brasileira dos Autores Teatrais.

Falabella, Miguel. 1992. No coração do Brasil. Sociedade Brasileira dos Autores Teatrais. 


\section{Referências bibliográficas}

Barbosa, Pilar, M. Eugênia L. Duarte \& Mary Aizawa Kato. 2005. Null subjects in European and Brazilian Portuguese. En Journal of Portuguese Linguistics 4, 11-52. Universidade de Lisboa.

Biberauer, Teresa. 2010. Semi pro-drop languages, expletives and expletive pro reconsidered. En Teresa Biberauer, Anders Holmberg, Ian Roberts \& Michelle Sheehan (eds.), Parametric Variation: null subjects in Minimalist theory. 153-199. Cambridge: Cambridge University Press.

Chomsky, Noam. 1981. Lectures on Government and Binding, Dordrecht: Foris.

Cyrino, Sônia, M. Eugênia L. Duarte \& Mary A. Kato. 2000. Visible subjects and invisible clitics in Brazilian Portuguese. E Mary Aizawa Kato \& Esmeralda V. Negrão (eds.), Brazilian Portuguese and the Null Subject Parameter. 55-104. Frankfurt: Vervuert/Iberoamericana.

Duarte, M. Eugênia L. 1993. Do pronome nulo ao pronome pleno: a trajetória do sujeito no português do Brasil. En Ian Roberts \& Mary Aizawa Kato (eds.), Português Brasileiro: uma viagem diacrônica. 7-128. Campinas: Editora da Unicamp.

Duarte, M. Eugênia L. 1995. A perda do princípio "Evite Pronome" no português brasileiro, Universidade Estadual de Campinas, Unicamp, Brasil. (Tese de doutoramento inédita).

Duarte, M. Eugênia L. 2000. The loss of the Avoid Pronoun principle in Brazilian Portuguese. En Mary Aizawa Kato \& Esmeralda V. Negrão (eds.), Brazilian Portuguese and the Null Subject Parameter. 17-36. Frankfurt am main/Madrid: Vervuert/Iberoamenricana.

Duarte, M. Eugênia L. 2007. Sobre outros frutos de um projeto herético: o sujeito expletivo e as construçôes de alçamento. En Ataliba de Castilho, Maria Aparecida Morais, Ruth Elisabeth Lopes \& Sônia Maria Cyrino (eds.), Descrição, história e aquisição do português brasileiro, 35-48. Campinas: Ed. Pontes.

Duarte, M. Eugênia L. (ed.). 2012. O sujeito nulo em peças de teatro (1843-1992): estudos diacrônicos, São Paulo: Parábola Editorial.

Duarte, M. Eugênia L., Gabriela Mourão \& Heitor Santos. 2012. Os sujeitos de terceira pessoa: revisitando Duarte 1993. En M. Eugênia L Duarte (ed.), O sujeito nulo em peças de teatro (18431992): estudos diacrônicos, São Paulo: Parábola Editorial.

Duarte, M. Eugênia L., Ulli. S. B. Fernandes. 2016. Construçóes de tópico-sujeito em contexto de variação e mudança. Web Revista SOCIODIALETO, v. 6, n. 18, 347-371.

Duarte, M. Eugênia L. 2019. O sujeito nulo referencial no português brasileiro e no português europeu. En Charlotte Galves, Mary A. Kato \& Ian Roberts (eds.), Português Brasileiro: uma segunda viagem diacrônica. Campinas: Ed. da Unicamp. (No prelo).

Felix, Thainá Santanna. 2017. O preenchimento da posição de sujeito com verbos inacusativos: uma análise sincrônica, UFRJ. (Monografia de graduação inédita).

Fernandes, Ulli, M. Eugênia L. Duarte \& Humberto Soares da Silva. 2015. Análise diacrônica da ordem V-DP/DP-V com verbos inacusativos no português brasileiro, Revista Philologos v. suplemento, UERJ, 418-428.

Ferreira, Marcelo B. 2000. Argumentos nulos em português brasileiro, UNICAMP, Campinas, Brasil. (Dissertação de mestrado inédita).

Henriques, Fernando P. 2012. Construçóes com verbos de alçamento que selecionam um complemento oracional. En Maria Eugênia L. Duarte (ed.), O sujeito nulo em peças de teatro (1843-1992): estudos diacrônicos. 101-120. Sáo Paulo: Parábola Editorial. 
Henriques, Fernando P. 2013. Construçôes com verbos de alçamento que selecionam um complemento oracional: uma análise comparativa do PB e PE, UFRJ. (Tese de doutoramento inédita).

Henriques, Fernando Pimentel \& M. Eugênia L. Duarte. 2006. Uma análise comparativa das construçôes com verbos de alçamento na fala e na escrita padrão. En Anais do IX Congresso Nacional de Linguistica e Filologia, 189-197.

Holmberg, Anders. 2010. Null subject parameters. En Teresa Biberauer, Anders Holmberg, Ian Roberts \& Michelle Sheehan (eds.), Parametric Variation: null subjects in Minimalist theory. 88-124. Cambridge: Cambridge University Press.

Holmberg, Anders, A. Nayudu, \& Michelle Sheehan. 2009. Three partial null-subject languages: a comparison of Brazilian Portuguese, Finnish \& Marathi. Studia Linguistica, 63: 59-97.

Holmberg, Anders \& On-Usa Phimsawat. 2017. Truly Minimal Pronouns. Diadorin: Revista de Estudos Linguísticos e Literários, n. 19, v. Especial, 11-36.

Kato, Mary Aizawa \& M. Eugênia L. Duarte. 2014. A variação entre construçôes finitas pessoais e impessoais no português brasileiro, Revista Sociodialeto 4 (12), 153-177.

Lopes, Célia. 2003. A inserção de 'a gente’ no quadro pronominal do português. Vol. 18. Frankfurt/Madrid: Vervuert/Iberoamericana.

Li, Charles-N. \& Sandra Thompson. 1976. Subject and topic: a new typology of language. En C-N Li (ed.) Subject and Topic, 457-489. New York: Academic Press.

Marins, Juliana. 2009. O Parâmetro do Sujeito Nulo: uma análise contrastiva entre o português e o italiano, Universidade Federal do Rio de Janeiro. (Dissertação de mestrado inédita).

Marins, Juliana, Soares da Silva \& M. Eugênia L. Duarte. 2017. Revisiting Duarte (1995): For a gradiente analysis of indeterminate subjects. Diadorin: Revista de Estudos Linguísticos e Literários, $n$. 19, v. Especial, 140-172.

Martins, Ana Maria \& Jairo Nunes. 2005. Raising issues in Brazilian and European Portuguese. Journal of Portuguese Linguistics, 4, 53-77.

Martins, A. Maria \& Jairo Nunes. 2010. Apparent hyper-raising in Brazilian Portuguese: Agreement with topics across a finite CP. En E. Phoevos Panagiotidis (ed.), The Complementizer Phase: Subjects and Operators. 143-163. Oxford: Oxford University Press.

Paula, Mayara Nicolau. 2016. A ordem VS/SV e as interrogativas-Q no PE e no PB: uma análise diacrônica, Universidade Federal do Rio de Janeiro. (Tese de doutoramento inédita).

Pinheiro, Diogo \& Juliana Marins. 2012. A trajetória das interrogativas Qu clivadas e não clivadas no português brasileiro. En Maria Eugênia L. (ed.), O sujeito nulo em peças de teatro (1843-1992): estudos diacrônicos. 161-180. São Paulo: Parábola Editorial.

Pontes, Eunice. 1987. O Tópico no Português do Brasil, Campinas: Ed. Pontes.

Roberts, Ian \& Anders Holmberg. 2010. Introduction: parameters in Minimalist theory. En Teresa Biberauer, Anders Holmberg, Ian Roberts \&Michelle Sheehan (eds.), Parametric Variation: null subjects in Minimalist theory. 1-57. Cambridge: Cambridge University Press.

Santos, Danielle. 2008. A ordem VS/SV com verbos inacusativos: um estudo diacrônico, Universidade Federal do Rio de Janeiro. Dissertação de mestrado inédita.

Santos, Danielle \& Humberto Soares da Silva. 2012. Ordem V-DP/DP-V com verbos inacusativos. En M. Eugênia L. Duarte (ed.), O sujeito nulo em peças de teatro (1843-1992): estudos diacrônicos. 121-142. São Paulo: Parábola Editorial. 
Soares da Silva, Humberto. 2011. Evidências da mudança paramétrica em dados da Lingua-E: o sujeito pronominal no português e no espanhol, Universidade Federal do Rio de Janeiro. (Tese de doutoramento inédita)

Vargas, Amanda de S. 2012. A evolução na representação das estratégias pronominais de indeterminação en Maria Eugênia L. (ed.) O sujeito nulo em peças de teatro (1843-1992), 45-68.

Weinreich, Uriel, William Labov \& Marvin Herzog. 1968. Empirical foundations for a theory of language change. En W. Lehman. \& Y. Malkiel (eds.), Directions for historical linguistics. 97-195. Austin: University of Texas Press.

Zubizarreta, M. Luísa. 1998. Prosody, Focus, and Word Order. Cambridge, Mass: The MIT Press. 